\title{
AS PRINCIPAIS TEORIAS EXPLICATIVAS ACERDA DA ARTE RUPESTRE: O USO DA MAGIA NO PARQUE NACIONAL SERRA DA CAPIVARA-PI, BRASIL, UM ESTUDO DE CASO
}

\author{
Michel Justamand ${ }^{1}$, Suelly Amâncio Martinelli² y Gabriel Frechiani de Oliveira ${ }^{3}$
}

Recibido: 27 de marzo de 2018. Aceptado: 15 de octubre de 2018

\begin{abstract}
Resumo
O presente trabalho tem por finalidade abordar as principais teorias explicativas acerca da arte rupestre, explicanda as terminologias, objetivos e metodologia de trabalho dos segmentos teóricos abordados. Dentro desse contexto o trabalho consistiu em um levantamento bibliográfico e documental, associado a uma pesquisa de campo realizado no Parque Nacional Serra da Capivara, no estado do Piauí, Brasil. A principal justificativa para a elaboração desse trabalho é a necessidade de discutirmos as múltiplas visões presentes no estudo da arte rupestre, citando os autores e aproximações teóricas e metodológicas, devido ao grau de especialização e diversificação do estudos atualmente, levando em consideração alguns questionamentos que serão debatidos ao longo deste trabalho no decorrer deste artigo. Esperar-se contribuir para uma discussão acerca das múltiplas perspectivas de analisar a arte rupestre, relevando que visões diferentes podem fornecer uma análise holística das obras rupestres.

Palavras-chave: teoria e metodologia, arte rupestre, Parque Nacional Serra da Capivara
\end{abstract}

\begin{abstract}
The purpose of this work is to address the main explanatory theories about rock art, explaining the terminologies, objectives and work methodology of the theoretical segments addressed. Within this context the work consisted of a bibliographical and documentary survey, associated to a field research carried out in Serra da Capivara National Park, in the state of Piaui, Brazil. The main justification for the elaboration of this work is the need to discuss the multiple visions present in the study of rock art, citing the authors and theoretical and methodological approaches, due to the degree of specialization and diversification of the present studies, taking into account some questions that will be discussed in the course of this article. We hope to contribute to a discussion about the multiple perspectives of analyzing rock art, noting that different views can provide a holistic analysis of rock works.
\end{abstract}

Key Words: theory and methodology, rock art, Serra da Capivara National Park

\section{Resumen}

El presente trabajo tiene por finalidad abordar las principales teorias explicativas acerca del arte rupestre, explica las terminologías, objetivos y metodología de trabajo de los segmentos teóricos abordados. Dentro de ese contexto el trabajo consistió en un levantamiento bibliográfico y documental, asociado a una investigación de campo realizada en el Parque Nacional Serra da Capivara, en el estado de Piauí, Brasil. La principal justificación para la elaboración de este trabajo es la necesidad de discutir las múltiples visiones presentes en el estudio del arte rupestre, citando a los autores y aproximaciones teóricas y metodológicas, debido al

1 Universidade Federal do Amazonas - UFAM. Instituto de Natureza e Cultura - INC, de Benjamin Constant; E-mail: micheljustamand@yahoo.com.

2 Universidade Federal de Sergipe; E-mail: suellyamancio@hotmail.com.

3 Secretária da Educação do Estado do Piauí; E-mail: gfrechiani@hotmail.com. 
grado de especialización y diversificación de los estudios actualmente, teniendo en cuenta algunos cuestionamientos que serán debatidos a lo largo de este trabajo en el transcurso de este artículo. Esperar contribuir a una discusión acerca de las múltiples perspectivas de analizar el arte rupestre, destacando que diferentes visiones pueden proporcionar un análisis holistico de las obras rupestres.

Palabras clave: teoría y metodología, arte rupestre, Parque Nacional Serra da Capivara

\section{Introdução}

Os primeiros grupos humanos modernos (Homo sapiens) surgiram no continente africano por volta 200 mil anos atrás, o grande diferencial desses espécimes, junto com seu parente hominídeo (Homo erectus), era produtor de bens de culturais, fabricantes de utensilios para ajudar nas tarefas cotidianas de sobrevivência (produção de ferramentas líticas), como caçar, coletar, construir habitações, controle reprodutivo, pescar e lutar contra seus adversários, seja outros humanos ou animais perigosos (Gownlett 2007; Karlin y Julien 1996).

Esses grupos humanos migraram do continente africano para outros continentes, como Ásia, Europa, Oceania e América, povoando o planeta terra e se desenvolvendo culturalmente e biologicamente, foram se adaptando ao ambiente e encontrando soluções para contornar os principais problemas encontrados, sendo um sucesso adaptativo até os dias atuais (Bernardi 1978; Darwin 1974; Lewin 1999).

Seu pacote adaptativo era uma série de conhecimentos para produzir ferramentas para auxiliar nas atividades diárias, a partir de uma tecnologia oriunda das manufaturas de rochas, que foram aperfeiçoadas com o passar do tempo e transmitidas de geração em geração, uma memória coletiva através um sistema de comunicação, constituído de uma linguagem inteligível (um depósito cultural), como a construção de símbolos e significados (Clark 1985;
Evans-Pritchard 1972; Langaney et al. 2002; Leroi-gourhan 2001).

De acordo com Engels:

"O desenvolvimento do cérebro e dos sentidos ao seu serviço, a crescente clareza de consciência, a capacidade de abstração e de raciocínio, cada vez maiores, influenciaram, por sua vez, o trabalho e a palavra, estimulando cada vez mais o seu desenvolvimento e, quando o homem se separa definitivamente do macaco, este desenvolvimento continua em grau diferente e em diferentes direções entre os diversos povos e nas diferentes épocas, interrompido inclusivamente, às vezes, por agressões de carácter local ou temporal, mas avançado no seu conjunto a passos largos, consideravelmente impulsionado e orientado num sentido mais preciso por um novo elemento que surge com a aparição do homem acabado: a sociedade" (Engels 1975:12-13).

Arte é uma forma de externar essa memória coletiva, registrar os acontecimentos cotidianos de uma sociedade e/ou tentar uma ligação com o sobrenatural, arte é uma forma de expressão e comunicação, uma forma de abstração e demonstração do desenvolvimento cognitivo dos seres humanos, que são influenciados por fatores biológicos, de equilibração das ações, fatores sociais de coordenação interindividual e fatores de transmissão educativa e cultural (Hauser 1984; Piaget 1978). Os dois modos que possibilitariam realizar uma análise das obras de arte em geral são: 1) através de um viés estético, onde é analisado partir de padrões de forma, harmonia e técnica; 2) um viés de comunicação, a partir de uma análise semiótica 
da imagem, buscando significados (Layton 2001).

\section{De acordo com Hauser:}

"Uma obra de arte é um desafio; não a explicamos, ajustamo-nos a ela. Ao interpretá-la, fazemos uso dos nossos próprios objetivos e esforços, dotamo-la de um significado que tem a sua origem nos nossos próprios modos de viver e de pensar. Numa palavra, qualquer gênero de arte que, de fato, nos afete, torna-se, deste modo, arte moderna. As obras de arte, porém, são como altitudes inacessiveis. Não nos dirigimos a elas diretamente, mas contornamo-las. Cada geração as vê sob um ângulo diferente e sob uma nova visão, nem se deve supor que um ponto de vista mais recente é mais eficiente do que um anterior. Cada aspecto surge na sua altura própria, que não pode ser antecipada nem prolongada, $e$, todavia, o significado que uma obra assume para uma geração posterior é o resultado de uma série completa de interpretações anteriores" (Hauser 1973:11).

A principal dificuldade de analisar as obras de artes pré-históricas é tentar compreender o seu significado dentro de um contexto arqueológico, a perspectiva estética pode fornecer informações acerca seu designer e formatação, mas apenas pelo uso da semiótica podemos buscar uma interpretação e denotar um valor ou significado (Layton 2001).

Schmitz et al. (1997:10-11) refletem acerca dos autores das pinturas rupestres encontrados nos sítios de Serranópolis, no estado de Goiás, no intuito de conhecer seu modo de vida e suas intenções contidas naquelas mensagens nas rochas.

O desafio de analisar uma obra de arte não ocidental, a partir uma perspectiva ocidental pode acarretar uma série de problemas de intepretação, a interpretação sempre é subjetiva e está associada ao contexto do observador, gerando uma série de possibilidades (Guidon 1984). É possível comparar as experiências das pessoas do presente com as pessoas das sociedades pretéritas a partir de uma perspectiva
Etnoarqueológica? É possível compreender os significados contidos nas pinturas rupestres além da perspectiva estética e/ ou semiótica proposta por Layton (2001)? Quais são as principais explicações para os significados da arte rupestre produzida pelos grupos humanos do passado?

\section{Desenvolvimento}

As principais explicações para arte rupestre pré-histórica desde século XIX até os dias atuais estão segmentadas em sete principais núcleos de pensamento: $1^{\mathrm{a}}$ ) Arte pela Arte; $2^{a}$ ) Totemismo; $3^{a}$ ) Magia simpática da caça e fecundidade; $4^{a}$ ) Perspectiva Estruturalista; 5 ${ }^{\mathrm{a}}$ ) Arqueologia Cognitiva $\left.6^{a}\right)$ Neuropsicologia e Xamanismo; $7^{a}$ ) Arqueoastronomia, Antropologia Sensorial e Arqueoacústica (Sanchdrian 2005; Whitley 2005).

A primeira perspectiva, "Arte pela Arte", está relacionada ao período de descobertas da arte rupestre pré-histórica nas cavernas europeias no final do século XIX e início do século XX, onde a finalidade era visualizar essa arte de forma contemplativa e iconográfica, ressaltando os aspectos estéticos e caracterizados por uma tendência natural dos grupos se expressarem nos paredões rochosos de forma lúdica e reflexiva (Gombrich 2008; Hauser 2010). Os principais representantes dessa perspectiva são pesquisadores como: Gabriel Mortillet, Edouard Larter, Max Verworn (18631921), Édouard Piette (1827-1906), George Henri Luquet (1876-1965) e John Halverson (Berrocal y Fraguas-bravo 2009).

A segunda perspectiva, o "Totemismo", está conectado aos trabalhos antropológicos do pesquisar inglês James Frazer (1854-1941), no seu livro Totemism, de 1887. No caso, o totem era uma espécie de animal sagrado ligado a um parente do passado dos membros de uma comunidade, gerando uma ponte de ligação entre 
mundo natural e sobrenatural (Frau 1959; Frazer 1971; Evans-Pritchard 1972; Schmidt 1942). A prática do totemismo está presente em várias tribos indígenas americanas, sociedades nativas africanas, e grupos da Oceania, onde observa-se, na construção do totem por essas comunidades humanas, sua relação com o sobrenatural ${ }^{1}$ (Bernardi 1978; Durkheim 2009; Kroeber 1945; Tylor 1903).

A terceira perspectiva está relacionada à magia simpática da caça e da fertilidade, onde a prática de pintar e gravar figuras de animais nas cavernas está relacionada à busca por uma melhor caçada de animais e, consequentemente, uma alimentação mais farta para um grupo (Breuil 1963; Frazer 1956; Hawkes 1966; Maringer y Bandi 1952). Os principais pensadores dessa perspectiva eram os pesquisadores franceses Henri Breuil (1877-1961) e Raymond Lantier (1886-1980), com o livro Les hommes de la pierre ancienne, e o historiador francês Salomon Reinach (18581932), com seu artigo L'árt et la magie à propos des peintures et gravures de l'âge du renne, na revista L'Anthropologie, em 1903 (Breuil y Lantier 1951; Clark 1969; Magalhães 2011).

Lewin (1999) explica que a hipótese de "mágica da caça" teve uma forte influência até a década de 1960, seu principal problema consistia em explicar pinturas sobre os animais que não estavam incluídos na alimentação dos grupos humanos, que residiam nesses sítios arqueológicos, evidenciado pela ausência de ossos desses animais nos locais.

De acordo com Bahn:

"Although the French prehistorian Gustave Chauvet suggested as early as 1887 that prehistoric art had a magical motivation - injury to the engraved image bunging injury to the real animal - portable Paleolithic art was dismissed initially as mere decoration: art for art's sake. However, with the acceptance of authenticity of cave art in Europe and increasing ethnographic knowledge of Australian aboriginal art, more complex explanations began to emerge. Particularity influential was the view that art represented sympathetic hunting magic, an idea espoused in 1903 by Salomon Reinach, director of the Musée des Antiquités Nationales; through Breuil's influence, it was to dominate studies of prehistoric art for decades" (Bahn 1999a:124-125).

A quarta perspectiva está relacionada ao "estruturalismo e a dicotomia sexual", corpo teórico que está associado às ideias dos linguistas Ferdinand Saussure (18571913) e Roman Jakobson (1898-1982) e Claude Levi-Strauss (1908-2009), aplicados pelos arqueólogos André Leroi-Gourhan (1911-1986), Annette Laming-Emperaire (1917-1977) e Max Raphäel (1889-1952), promovendo uma renovação teórica e metodológica no campo da arte rupestre europeia, buscando aspectos imateriais contidas nas pinturas rupestres (Anati 2006; Bahn 1999b; Martinez 2014). O historiador alemão da arte Max Raphäel fez um levantamento acerca da arte nos abrigos paleolíticos da região de Dordonha, na França, na década de 1930, publicando o livro Prehistoric Cave Paintings em 1945 e antevendo o uso de ideias estruturalistas no estudo da arte rupeste, rechaçando a primazia da hipótese da magia da caça e fornecendo novos caminhos metodológicos, que foram aproveitados por André Leroi-Gourhan e Annette Laming-Emperaire nas décadas de 1950 e 1960 (Berrocal y Fraguas-bravo 2009).

Os principais argumentos de Max Raphäel sobre o entendimento da arte rupestre: a) questiona o valor dos paralelos etnográficos; b) sustenta que a dificuldade de acesso a muitas imagens subterrâneas apontavam intenções sagradas; c) nega qualquer forma de totemismo; d) aponta para uma mentalidade mais elaborada do pensamento dos grupos humanos no passado; e) sustenta que as figuras deveriam ser estudadas como composições planificadas, não apenas grafismos isolados, per- 
dendo a visão de todo o conjunto rupestre (Lewis-Williams 2005).

André Leroi-Gourhan (1968) estudou de forma sistemática as figuras na caverna de Lascaux, visando evidenciar associações, sobreposições, tipos de grafismo, a questão do dimorfismo sexual, localização dos grafismos no sítio, a topografia do sítio, as técnicas utilizadas na elaboração das pinturas e gravuras rupestres, construindo uma tipologia estilística para a arte pré-histórica europeia (Clottes 2008).

Sanchidrian afirma,

“(...) el logro del estructuralismo fue el demonstran una organización em el arte parietal', las críticas provienen del marco de su interpretación, es decir, del significado final de esa ordenácion. Hoy se tende a examinar conjuntos de cuevas de idêntica cronologia y/o en um ámbito territorial cercano, com el propósito de analizar sus semejanzas y diferencias; em este orden de cosas están las aportaciones de, entre otros, Vialou, Pellua y Sauvet" (Sanchidrian 2005:345).

A arqueologia cognitiva é um segmento oriundo das ideias da Nova Arqueologia, influenciada pelas ideias da antropologia cognitiva (etnociência), do funcionalismo, do determinismo ambiental, ênfase nos aspectos econômicos, buscando regularidades no registro arqueológico. O primeiro momento da arqueologia cognitiva (funcionalista) está situado entre as décadas de 1960 a 1970, onde buscavam rechaçar o relativismo cultural, o idealismo filosófico, enfatizar os aspectos econômicos ambientais, postulando a impossibilidade de recuperar as ideias contidas nas mentes primitivas, assim se distanciando dos aspectos imateriais da cultura e sendo capitaneado por Lewis Binford (Bahn y Renfrew 1993).

$\mathrm{O}$ segundo momento da arqueologia cognitiva é denominado de reação pós-processual ou arqueologia cognitiva interpretativista na década 1980, onde os arqueólogos Ian Hodder, Christopher Tilley e Michael Shanks criticaram a perspectiva funcionalista da arqueologia cognitiva com seu positivismo racionalista e adotaram as seguintes características: abordagem interpretativista, subjetiva e idealista, contida nas figuras dos pensadores Bennedito Croce (1866-1952), R.G. Collingwood (1889-1943), Claude Lévi-Strauss (19082009), Paul Ricoeur (1913-2005) e Paul Veyne (Karlin y Julien 1996; Shanks y Tilley 1992).

O terceiro momento da arqueologia cognitiva, denominada de processual, situa-se a partir de 1980, onde suas ideias funcionalistas foram revistas, adotando-se uma perspectiva racional e objetiva acerca na análise arqueológica, assim visando compreender o funcionamento das sociedades pretéritas a partir de um aparato técnico e científico que permitiria a realização de inferências sobre o passado. O principal objetivo da arqueologia cognitiva (nova antropologia ou etnociência) é identificar permanências no comportamento a partir vestígios arqueológicos, evidenciando um mapa cognitivo (símbolos) de cada sociedade estudada, assim adentrando dentro do universo de cada indivíduo, sendo possível realizar inferências e formular leis universais do comportamento humano (Johnson 2000; Karlin y Julien 1996; Sternberg 2000).

A finalidade dos arqueólogos cognitivos processuais é de estabelecer relações entre os símbolos que são encontrados nos registros arqueológicos, em detrimento do significado dos símbolos, pois esses estariam perdidos com seus portadores no passado. Logo, os vários aspectos que os simbolos podem ser utilizados são: $1^{\circ}$ ) modelo, no sentido de um comportamento coerente estruturado; $2^{\circ}$ ) planejamento e o espaço físico; $3^{\circ}$ ) medição, dispositivos de medida e unidade de tempo; $4^{\circ}$ ) relações sociais; o uso dos símbolos para estruturar e regular o comportamento social; $5^{\circ}$ ) o sobrenatural, a necessidade de estabelecer ligação com o outro mundo; $6^{\circ}$ ) represen- 


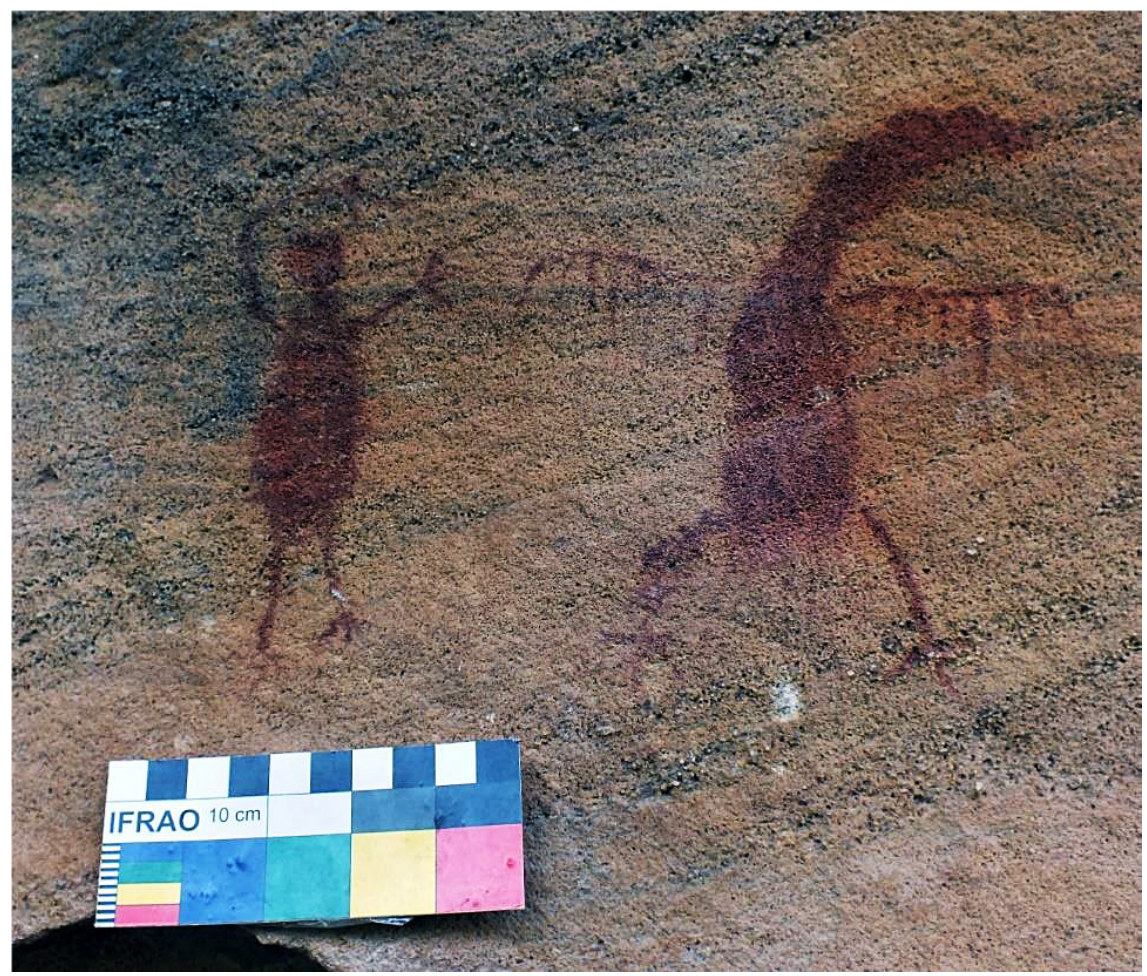

Figura 1. Interação entre a representação de um pássaro um antropomorfo. Toca do Baixão das Mulheres III, Parque Nacional Serra da Capivara, Brasil. Fonte Gabriel Oliveira, 2017.

tação, produção e utilização da realidade (Karlin y Julien 1996; Martinez 2000). Os principais representantes da arqueologia cognitiva processual são os arqueólogos: Colin Renfrew; Steven Mithen e Michael Schieffer.

A sexta perspectiva, "neuropsicologia e xamanismo", está correlacionada com relatos etnográficos de tribos indígenas do passado e do presente, nos quais os membros passam por uma sensação de experiência extracorpórea e onde são feitas revelações (Cruls 1976; Lowie 1972; Sanchidrian 2005). O ritual é realizado por um xamã, que, através uma substância alucinógena, conduz o participante a um estado alterado de consciência, o qual ele é guiado por um animal-condutor (pássaro), que serve de elo entre o mundo natural e sobrenatural (Correia 2009; Franch 1982) (ver figura 1).

As cavernas eram locais de cerimônias e consideradas sagradas pelos membros das tribos indigenas, onde se desenvolvia um ritual introspectivo e de autoconhecimento, as pinturas rupestres poderiam validar essa perspectiva sobrenatural (Beltrão 2000; Clottes 2008; Lewis-Williams 2005). As investigações etnográficas feitas pelo pesquisador Gerardo Reichel-Dolmatoff (1912-1994) (1976) demonstraram que era feito uso de compostos alucinógenos (yajé) em forma de um ritual religioso, com a intenção de experimentar estados altera- 


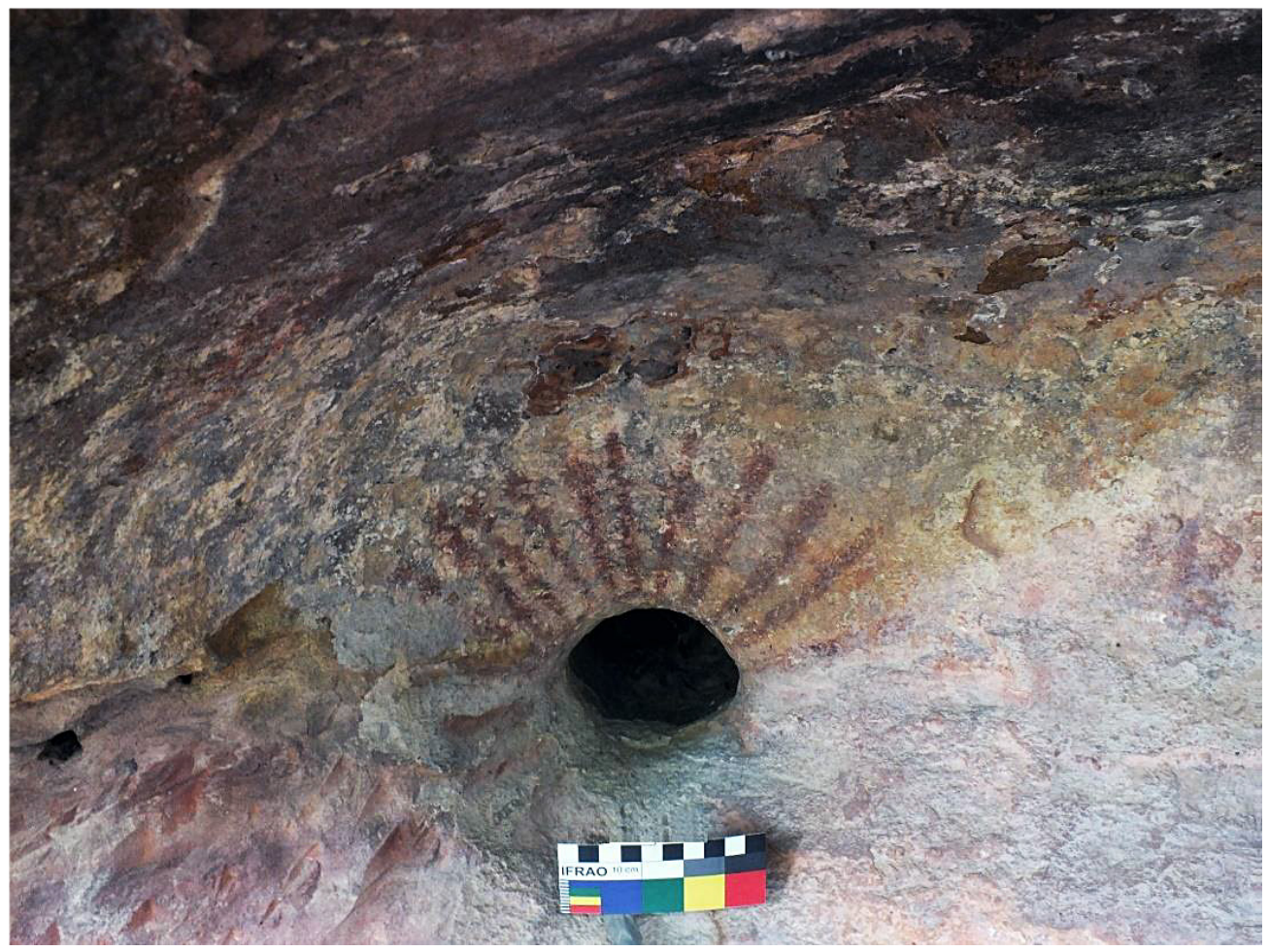

Figura 2. Orificio no paredão rochoso representando uma passagem. Sítio Toca da Roça do Sítio do Brás I, Parque Nacional Serra da Capivara, Brasil. Fonte Gabriel Oliveira, 2017.

dos de consciência na tribo dos Tukanos, na região do Alto rio Negro, Amazônia brasileira (ver figuras 2 e 3 ).

$\mathrm{Na}$ literatura acerca dos grupos indigenas sul-americanos encontra-se referências dessa prática, que estão contidos nos seus mitos cosmogônico e antropogônio, como na tribo Tapirapé, que são designados como médico-feiticeiros e sendo capaz realizar intervenções sobrenaturais (Baldus 1979; Schaden 1959,1969; Wagly 1976); os médico-feiticeiros entre os índios Krahó são outro exemplo da prática do xamanismo (Schultz 1976a; 1976b); a religião dos Terêna, no estado de Mato Grosso, também apresenta características da prática xamânica; os Tampi-táua também recorrem a práticas xamânicas (Baldus 1976; 1969); os parakañas, no estado do Pará, também recorrem a esse tipo de prática religiosa, demonstrando uma extensa recorrência nas tribos indigenas brasileiras (Fausto 2001).

A sétima perspectiva está relacionada com a "arqueoastronomia, arqueologia dos sentidos e arqueoacústica". Arqueoastronomia é um segmento do estudo da arte rupestre que visa correlacionar os fenômenos celestes aos significados da arte rupestre, postulando que os grupos humanos do passado detinham conhecimentos astronômicos e uma noção de espaço e tempo, os principais problemas dessa perspectiva estão no campo metodológico e o uso ex- 


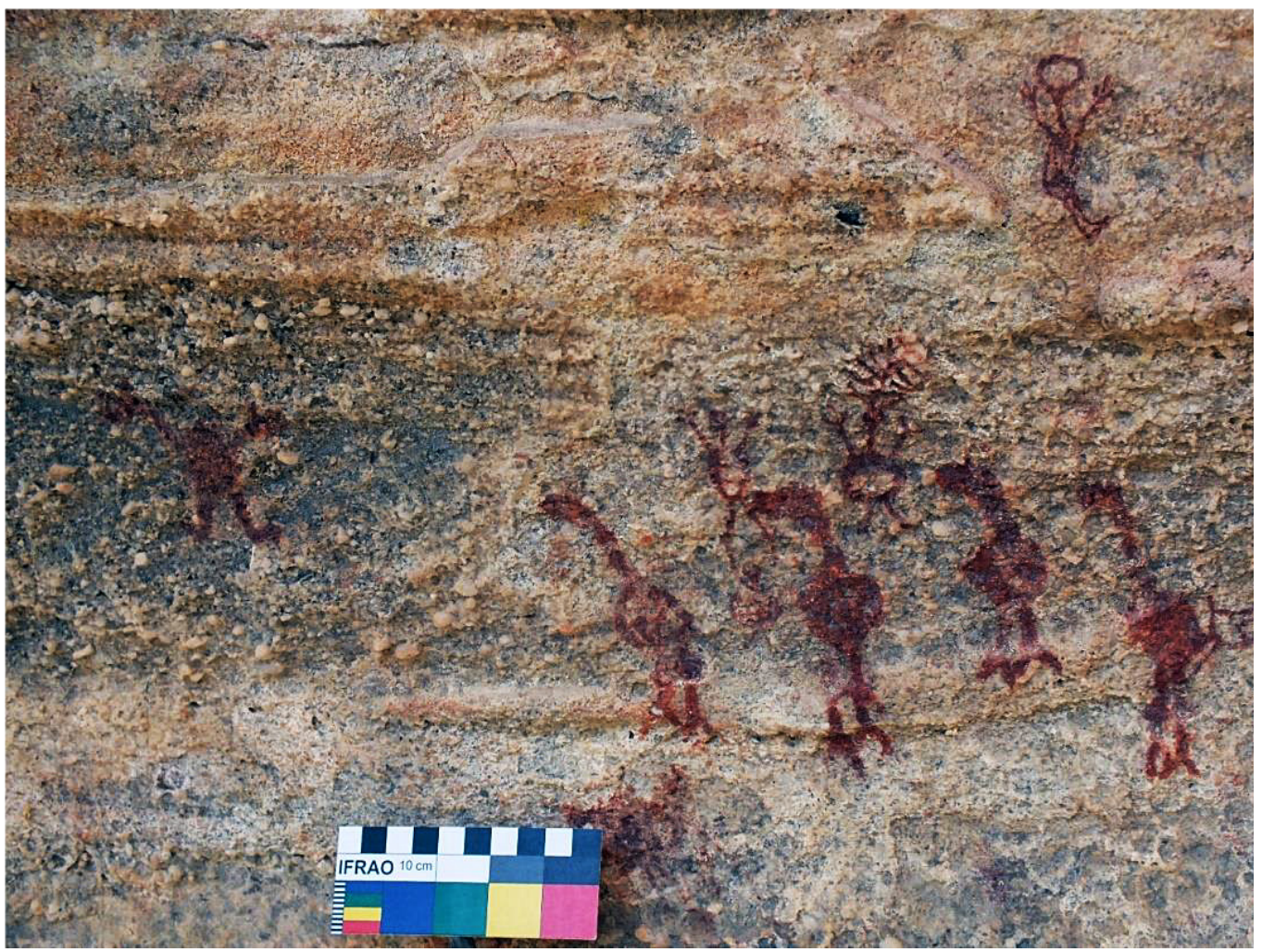

Figura 3. Ritual coletivo de magia e possivel transformação dos antropmorfos em biomorfos. Toca do Baixão do Perna III, Parque Nacional Serra da Capivara, Brasil. Fonte Gabriel Oliveira, 2017.

cessivo de analogias (Beltrão y Perez 2006; Nader 2004; Withley 2005). Beltrão (2000) afirma que as pinturas rupestres contidas na Toca do Cosmos representariam a ideia de um relógio solar, onde estariam divididos 24 segmentos que corresponderiam à divisão do dia ou uma imagem representando o movimento solar durante o dia.

A arqueologia Sensorial é uma disciplina oriunda da antropologia dos sentidos, na qual os sentidos são utilizados para a compreensão da realidade social, logo adotando uma visão subjetiva, idealista e interpretativa do registro arqueológico (Classen 1997; Pellini 2010). A visão multissensorial e a confiança exacerbada nos sentidos causam alguns problemas de aceitação metodológica desse tipo de perspectiva no meio acadêmico, em especial no sentido de reproduzir as experiências do passado a partir das experiências do presente (Fahlander y Kjellström 2010; Pellini 2015). Classen (1998) demonstra a importância dos sentidos para a compreensão da experiência, onde a privação da visão pode estimular outros sentidos a trabalharem de uma forma diferenciada, proporcionando uma melhor experimentação da realidade.

Para Pellini,

"Como arqueólogos, estamos acostumados 
em nosso dia a dia a registrar e interpretar sítios arqueológicos, a descrever detalhadamente objetos, a desenhar perfis estratigráficos, a fotografar, a ler e a escrever. Estamos acostumados a criar histórias, imagens e discursos sobre o passado. Mas, se pensarmos que o que criamos sobre o passado é baseado nos fatos que registramos, nossas interpretações partem, na realidade, não apenas da materialidade do sitio, do objeto, da paisagem, mas principalmente da materialidade do discurso. O passado não é apenas aquilo que é registrado, mas é aquilo produzido através da observação, da documentação, das práticas de escrever, fotografar, registrar. (...) talvez o principal potencial da Arqueologia Sensorial seja sua capacidade de reformular o próprio campo da Arqueologia, libertando a disciplina de suas correntes modernistas e ocularcentristas e adotando uma prática multissensorial e mnemónica" (Pellini 2016:29).

A arqueoacústica é um campo da arqueologia que estuda a relação do som e os sítios arqueológicos, onde grupos humanos usavam para se comunicar ou realizar rituais musicais (Oliveira et al. 2013). Assim, existindo a possibilidade de grupos humanos do passado terem construído monumentos megalíticos, levando em consideração a dispersão do som no local, no intuito de aumentar a potência e criar um maior efeito sonoro, influenciando o padrão de desenvolvimento do cérebro humano (Cook et al. 2008). Brum, Boivin e Fullagar (2006) demonstram a partir de um caso em um complexo de sítios neoliticos Sanganakallu-Kupga, no sul da Índia, onde autores observaram uma relação entre as gravuras rupestres e propriedades acústicas nas rochas locais, identificando os padrões de percussão e comparando com os grafismos encontrados no local.

De acordo com Pucci,

"Parece possivel afirmar que existe uma forte ligação entre o surgimento da música e a linguagem, hipótese que situa o despertar do sentido musical em tempos bastante remotos. Mas, mesmo quando a música se mantém oral, não é linguagem da razão, é expressão das grandes forças misteriosas que animam o homem. Também a música dos primeiros homens certamente estava carregada de sentidos, dos sentidos simbolizados nos desenhos e pinturas feitos nas pedras, nas cavernas, e hoje podem nos servir de inspiração para outras ideias musicais" (Pucci 2006:260).

Rifkin (2009) expõe um estudo em Klipbak, na África do Sul, acerca da relação de gravuras rupestres, a construção da paisagem e a acústica, afirmando que a música tem o poder de reforçar e manter a identidade dos grupos, a partir de experiências constatadas em várias comunidades e, assim, concluindo que a música, a dança, o canto, a acústica e o movimento fazem parte de um processo ritual. A combinação de todos esses elementos contribuiria para o processo de contato com o sobrenatural, sustentando a tese de que o som percussivo fazia parte desse ritual e estaria relacionado com as gravuras rupestres do local.

\section{O contexto do parque nacional serra da capivara: um estudo de caso}

O Parque Nacional Serra da Capivara está delimitado entre os municípios de João Costa, Coronel José Dias, São Raimundo Nonato e Brejo do Piauí, na região Sudeste do Piauí, compreendendo uma área de quase 130.000 hectares e um perímetro de $214 \mathrm{~km}^{2}$, sendo criado durante o governo do presidente João Baptista Figueiredo, em 1979 (Araújo et al. 1998).

As pesquisas científicas realizadas na região apresentaram resultados importantes na construção do conhecimento da arqueologia pré-histórica brasileira, atualmente estão catalogados 1.335 sitios arqueológicos no local, onde há 184 sítios com vestígios cerâmicos, 946 sítios de pinturas rupestres, 206 sítios de pinturas e gravuras, e 80 sítios de gravuras (Guidon 2014; Maranca y Martin 2014). Os vestígios paleontológicos são também um seg- 

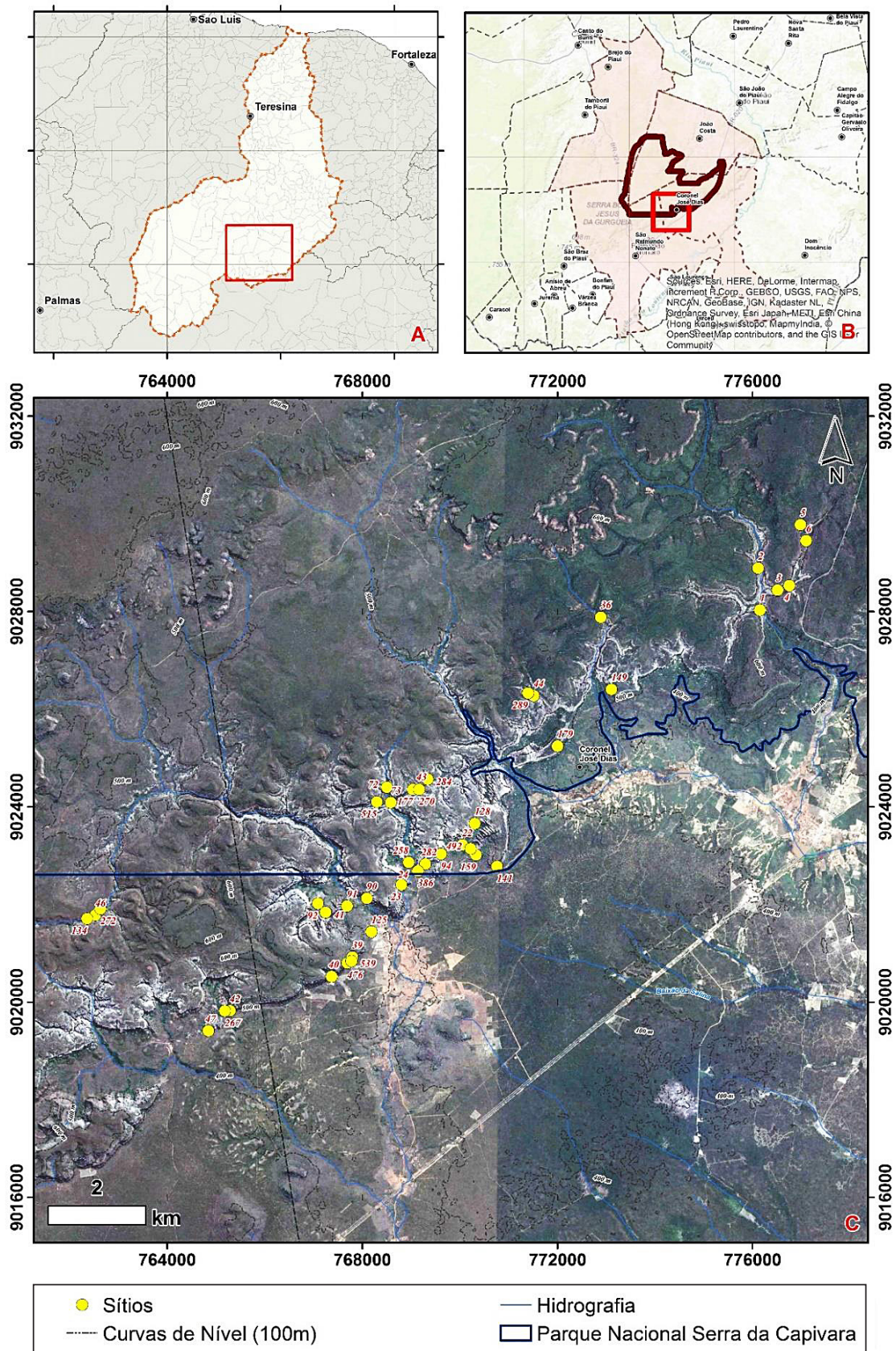

Figura 4. Localização dos 51 sítios arqueológicos selecionados para a pesquisa. Fonte Gabriel Oliveira, 2016. 
mento relevante das investigações científicas no local, já foram encontrados mais 7.000 fósseis e identificadas mais 60 espécies de animais, na qual 30 espécimes já são considerados extintos (Guerin y Faure 2014).

Foi realizado um levantamento de arte rupestre em 51 sítios do Parque, mais especificamente nas regiões da Serra Talhada, Serra Branca, Veredão, Congo e Serra da Capivara, buscando pinturas e gravuras rupestres que indicassem a prática da magia (ver figuras 4, 5, 6 e 7, 8, 9 e 10 abaixo).

Nas figuras 5 e 6 observar-se uma es- pécie de ritual coletivo entorno de um fitmorfo, uma espécie de uma árvore, cena bastante recorrente na região, sendo designada como uma "cena da árvore".

$\mathrm{Na}$ figura 7 observar-se uma espécie de transformação de um antropomorfo em um biomorfo, nota-se o crescimento de uma galhardo cabeça do antropomorfo, podendo ser um ritual de magia. Enquanto na figura 8 , nota-se uma cena ritual coletiva, podendo ser uma espécie de dança a partir uns instrumentos localizados nas mãos dos antropomorfos.

Na figura 9, nota-se a presença de uma antropomorfo usando uma espécie de ma-

Figura 5. Cena do ritual do árvore. Sítio Toca do Baixão do Vaca, Parque Nacional Serra da Capivara, Brasil. Fonte Gabriel Oliveira, 2017

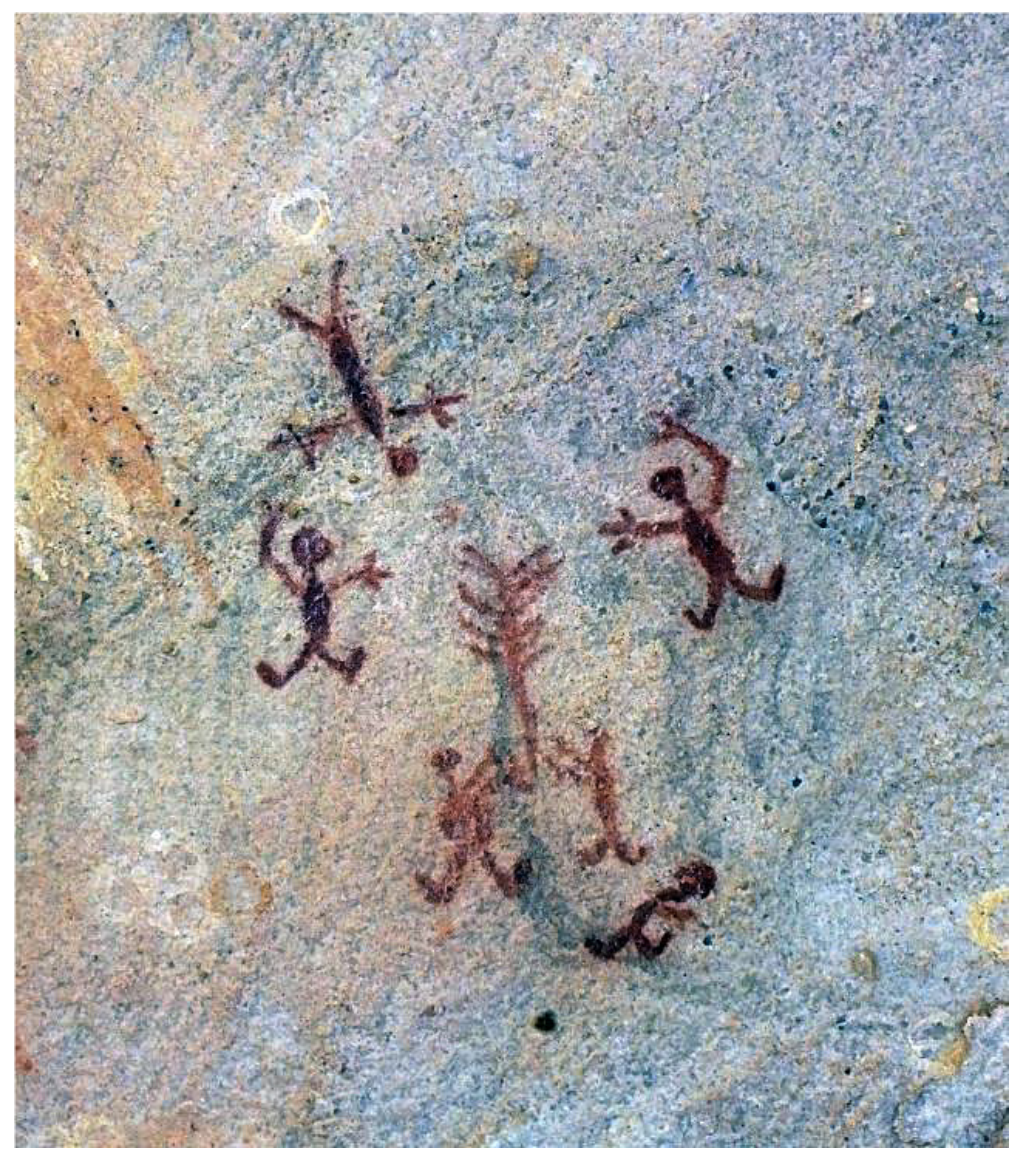



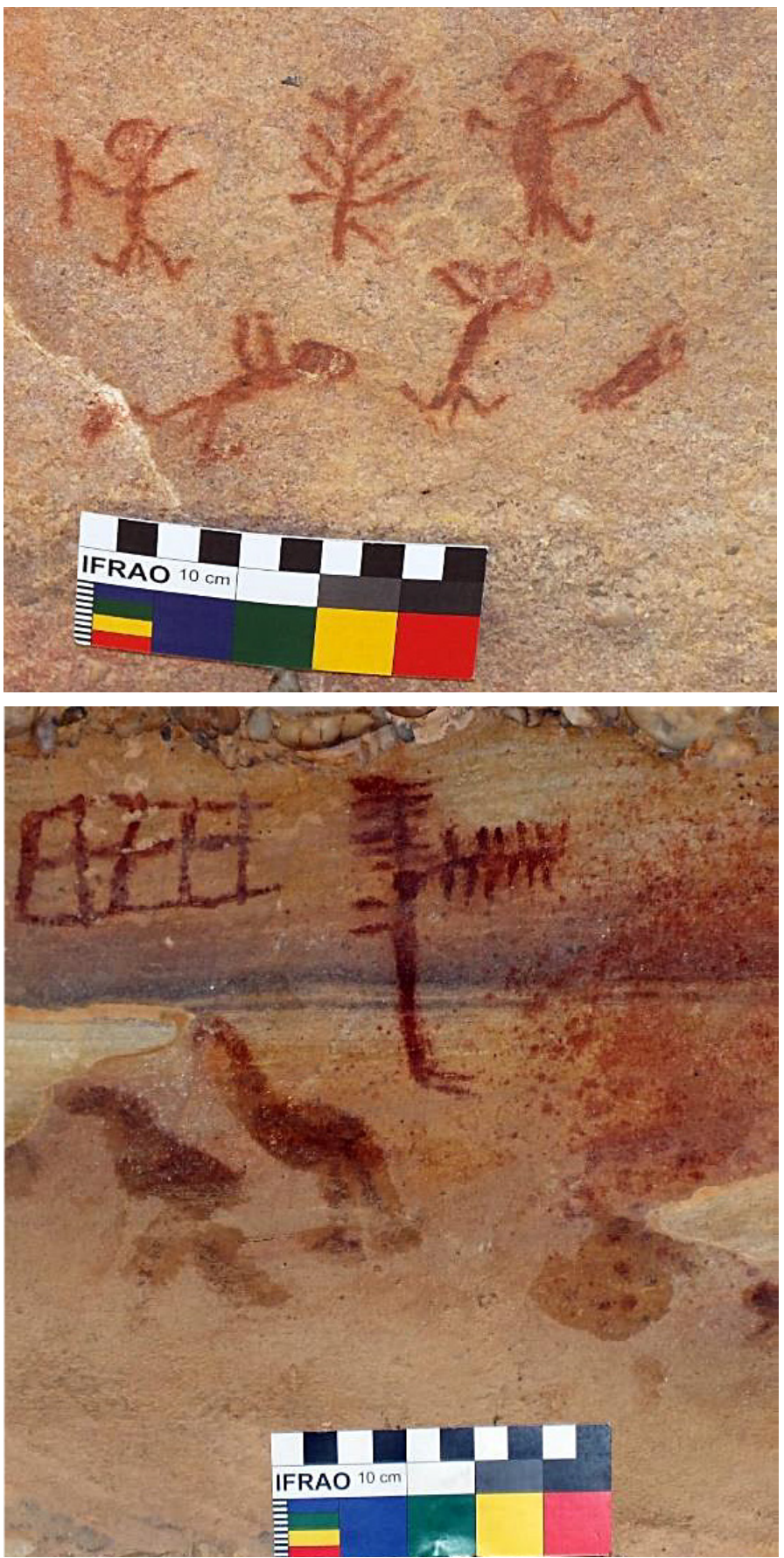

Figura 6. Cena do ritual do árvore. Sítio Toca do Baixão do Vaca, Parque Nacional Serra da Capivara, Brasil. Fonte Gabriel Oliveira, 2017.

Figura 7. Cena da transformação de um antropomorfo em biomorfo. Sítio Toca do Barro, Parque Nacional Serra da Capivara, Brasil. Fonte Gabriel Oliveira, 2017. 


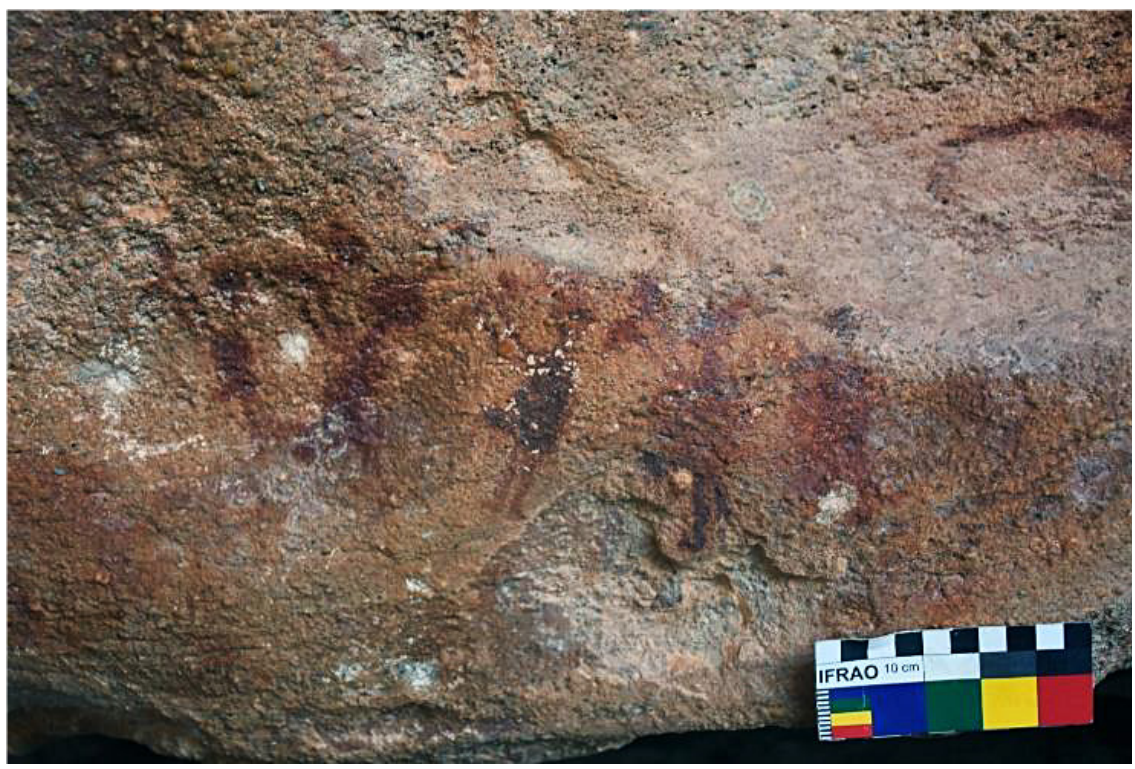

Figura 8. Cena de um ritual coletivo. Sítio Toca da Invenção, Parque Nacional Serra da Capivara, Brasil. Fonte Gabriel Oliveira, 2017.

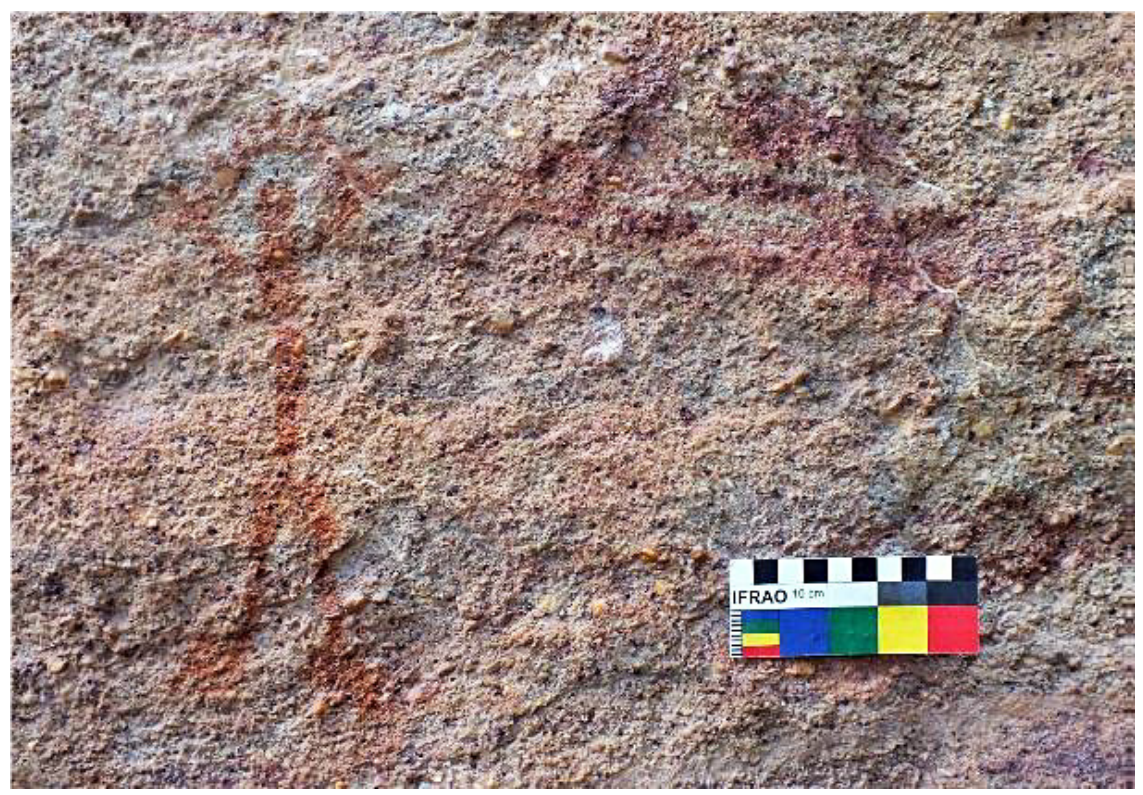

Figura 9. Antropomorfo usando magia. Toca do Carlindo II, Parque Nacional Serra da Capivara, Brasil. Fonte Gabriel Oliveira, 2017. 


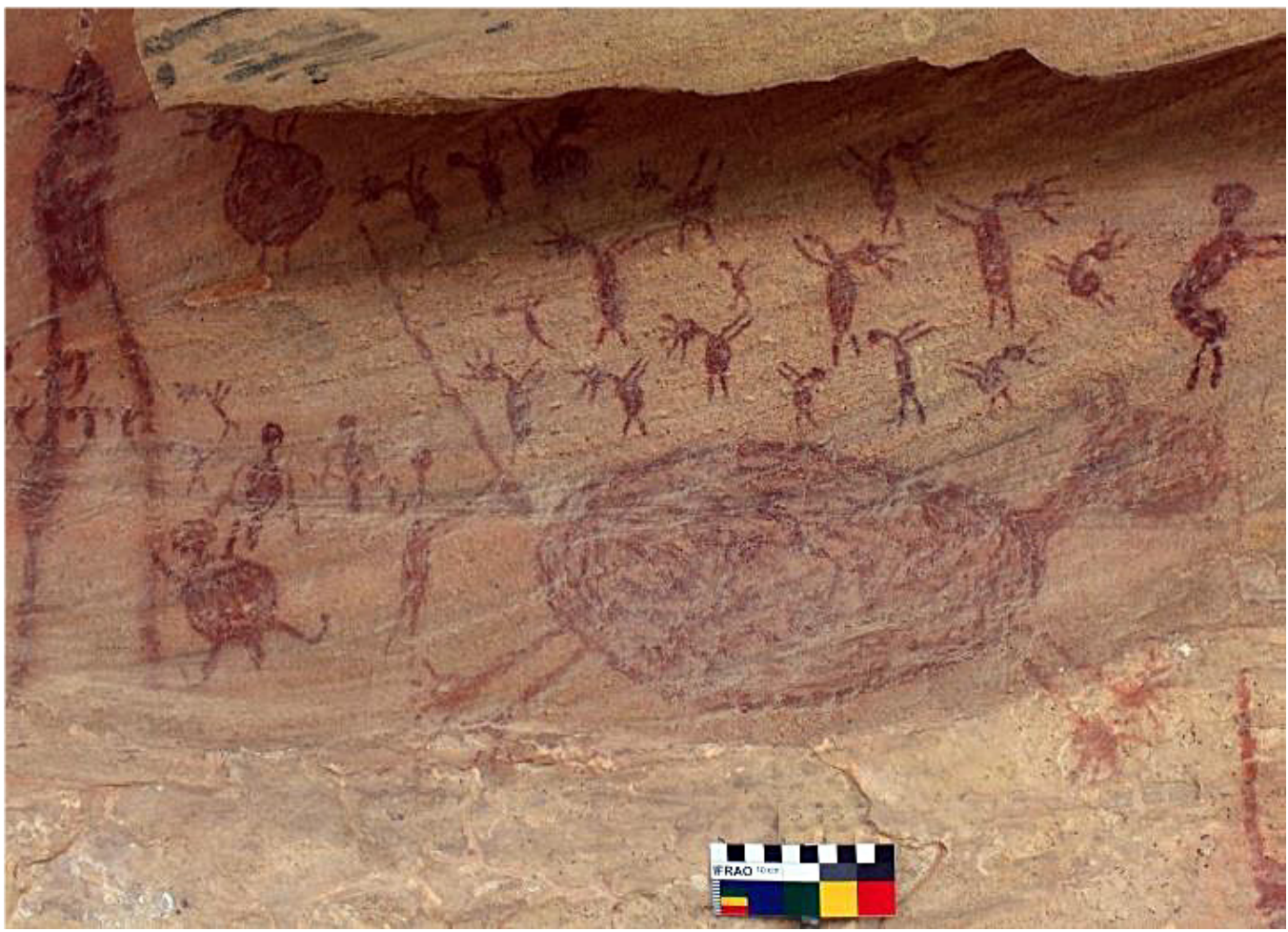

Figura 10. Cena de um ritual coletivo. Sítio Toca de cima do fundo da Pedra Furada., Parque Nacional Serra da Capivara, Brasil. Fonte Gabriel Oliveira, 2017.

gia ou poder concentrado nas suas mãos, uma espécie de feiticeiro. Enquanto a figura 10 aponta para uma espécie de transe coletivo com a presença vários antropomorfos dispostos, sendo uma espécie de ritual.

\section{Considerações finais}

O estudo das principais teorias explicativas no campo da arte rupestre, permite uma compreensão holística do fenômeno no espaço e no tempo. Dentro desse contexto, a arte rupestre é sistema de comunicação dos primeiros grupos humanos no passado, caracterizado pelo uso da escrita pictográfica e provavelmente funcionando como uma espécie de memória social desses autores, registrando seus principais acontecimentos, personagens e práticas culturais.

O estudo da arte rupestre possibilita um melhor entendimento do funcionamento dos grupos humanos do passado, aspectos como tecnológicos, sua fauna, sua flora suas cerimonias religiosas, seus conflitos e sua habilidade de projetar o mundo a sua volta, um admirável mundo novo.

Dentro do Parque Nacional encontra-se a presença de cenas e figuras que remetem ao uso ou prática da magia pelas sociedades pré-coloniais, demonstrando um processo de abstração e construção da realidade por essas sociedades humanas. 


\section{Notas}

1. Lowie (1972:102-103) afirma que "E1 totemismo está ampliamente disperso, ya que se lo encuentra en América, Australia, Melanesia, África y partes de Ásia. Tan extensa difusión impresionó profundamente a los primeros estudiosos que investigaron los datos correspondientes, quienes siguiendo la tendencia teórica de su época dieron por sentado, sin profundizar sus indagaciones, que todos los fenómenos clasificados como totemismo representaban procesos psicológicos idénticos, originados en diferentes zonas de manera independiente a través de la unidad psíquica del género humano".

2. Arte parietal: “(..) arte localizada em las paredes o techos de una cavidade, comúnmente una caverna sedimentaria." (Bednarik et al. 2003:115).

\section{Referências}

ANATTI, E. 2006. El arte. Orígenes del arte. En Artes y civilizaciones, editado por J. Suareda, pp 47-67. Lunwerg y Jaca Book SpA, Milão.

BAHN, P.G. 1999a. The Cambrige Illustrated History of Archaeology. The Press Syndicate of the University of Cambridge, Cambridge.

BAHN, P.G. 1999b. The Cambrige Illustrated History of Prehistoric of Art. The Press Syndicate of the University of Cambridge, Cambridge.

BALDUS, H. 1976. O xamanismo na aculturação de uma tribo tupí do Brasil Central. En Leituras de Etnologia Brasileira, pp. 455-462. Companhia Editora Nacional, São Paulo.

BALDUS, H. 1979. Ensaios de Etnologia Brasileira. Editora Nacional, São Paulo.

BEDNARIK, R.; A. ACHRATI; M. CONSENS; F. COIMBRA; G. DIMITRIADIS; T. HUISHENG; A. MUZZOLINI; D. SEGLIE; y Y.A. SHER. 2003. Rock Art Glossary. A multilingual dictionary.
Brepols Publishers, Turnhout.

BELTRÃO, M.C. 2000. Ensaio de arqueologia: uma abordagem transdisciplinar. Zit Gráfica e Editora, Rio de Janeiro.

BELTRÃO, M.C. y R.A.R. PEREZ. 2006. Signos e simbolos: uma linguagem ancestral. En Terra Brasilis: Pré-História e arqueologia da psique, editado por $\mathrm{M}$. Calila e M. Fleury de Oliveira, pp.73-81. Editora Paulus, São Paulo.

BERNARDI, B. 1978. Introdução aos estudos Etno-antropológicos. Editorial Presença, Lisboa.

BERROCAL, M.C. y A. FRAGUAS-BRAVO. 2009. Introducción al arte rupestre prehistórico. Luana Ediciones, Madrid.

BOIVIN, N.; A. BRUMN y R. FULLAGAR. 2006. Signs of life: engraved stone artefacts from neolithic South India. Archaeological Journal 16(2):165-190.

BREUIL, H.A. y R. LANTIER. 1951. Les Hommes de la Pierre Ancienne (Paleolithique et Mesolithique). Payot, Paris.

BREUIL, H.A. 1963. Arte paleolítica. En O homem antes da escrita editado por A. Varagnac, pp.107-127. Companhia Editora do Ninho, Lisboa.

CLARK, G. 1985. A Identidade do homem, uma exploração arqueológica. Jorge Zahar Ed, Rio de Janeiro

CLARK, G. 1969. Os caçadores da idade da pedra. Editorial Verbo, Lisboa.

CLASSEN, C. 1997. Foudantions for an anthropology of senses. Blackwell Publishers, Oxford.

CLASSEN, C. 1998. The Color of Angels. Routledge, London.

ClOTTES, J. 2008. Cave Art. Phaidon Press Limited, London.

CORREIA, A.C.B. 2009. Engraved world: A contextual analysis of figures and markings on the rocks of south-eastern Piaui, Brazil. 366 f. Tese Doutorado em Filosofia na Arqueología, School of Historical Studies Newcastle University, New Castle.

CRULS, G.H. 1976. Amazônica: aspectos 
da flora, fauna, arqueologia e etnografia indigenas. José Olympio, Rio de Janeiro.

DARWIN, C. 1974. A origem do homem e a seleção sexual. Trad. Atílio Cancian e Eduardo Nunes. Hemus, São Paulo.

DURKHEIM, E. 2009. As formas elementares da vida religiosa: o sistema totémico na Austrália. trad. Paulo Neves. Martins Fontes, São Paulo.

ENGELS, F. 1975. O papel do trabalho na transformação do macaco em homem. En Consequências da evolução humana. Cadernos de teoria e conhecimento 8:5-28.

EVANS-PRITCHARD, E.E. 1972. Antropologia social. Livraria Martins Fontes, Lisboa.

FAHLANDER, F. y A. KJELLSTRÖM. 2010. Beyond Sight: Archaeologies of Sensory Perception. En Making Sense of Things: Archaeologies of Sensory Perception, editado por F. Fahlander y A. Kjellström, pp. 1-13 Stockholm University, Stockholm.

FRANCH, J.A. 1982. Arte y Antropologia. Alianza editorial S.A, Madrid.

FRAU, S.C. 1959. Prehistoria de América. Editorial Sudamericana, Buenos Aires.

FRAZER, J.G. 1956. La rama dorada: $M a-$ gia y religión. Fondo de Cultura Económica, Cidade do México.

FRAZER, J. G. 1971. El Totemismo: estúdio de etnografia comparada. Juan Pablos Editor, Cidade do México.

GOMBRICH, E. 2008. A História da Arte. LTC, Rio de Janeiro.

GOWNLET, J. 2007. Arqueologia das primeiras culturas: A alvorada da humanidade. Printer Industria Gráfica, Madrid.

GUÉRIN, C. y M. FAURE. 2014. Os Biomas e as Sociedades Humanas na Pré-história da região do Parque Nacional Serra da Capivara. En Os Biomas e as Sociedades Humanas na Pré-história da região do Parque Nacional Serra da Capi- vara. vol. II, editado por A.M. Pessis, N. Guidon y G. Martin, pp. 140-168. A\&A Comunicação, São Paulo.

GUIDON, N. 1984. Arte Rupestre: Uma síntese do procedimento de pesquisa. Arquivos do Museu de História Natural 7:341-352.

GUIDON, N. 2014 A. A Fundação Museu Homem Americano e o Parque Nacional Serra da Capivara: um relato sucinto de quatro décadas de pesquisas. En Os Biomas e as Sociedades Humanas na Pré-história da região do Parque Nacional Serra da Capivara, editado por A. Pessis, N. Guidon y G. Martin, pp. 2644. A\&A Comunicação, São Paulo.

HAUSER, A. 1973. Teorias da Arte. Presença, Lisboa.

HAUSER, A. 1984. A arte e a sociedade. Presença, Lisboa.

HAUSER, A. 2010. História Social da Arte e Literatura. Martins Fontes, São Paulo

HAWKES, J. 1966. Prehistoria. História de la humanidad. Suadamericana, Buenos Aires. JOHNSON, M. 2000. Teoría arqueológica: una introducción. Ariel, Barcelona.

KARLIN, C. y C. JULIEN. 1996. Prehistoric: ¿a cognitive archaeology? The ancient mind: Elements of cognitive archaeology, editado por C. Renfrew y E. Zubrob, pp.152-164. Cambridge University Press, Cambridge,

KROEBER, A. 1945. Antropologia General. Fundo de Cultura Econômica, Cidade do México.

LANGANEY, A.; J. CLOTTES; J. GUILAINE y D. SIMMONET. 2002. A mais bela história do homem: de como a Terra se tornou humana. DIFEL, Rio de Janeiro.

LAYTON, R. 2001. Antropologia da Arte. Edições 70, Lisboa.

LARTET, E. 1861. Nouvelles recherches sur la coexistence de l'homme et des grands mammifères fossiles réputés caractéristiques de la dernière période géologique, Annuaire Sciences Nature- 
Justamand M., Martinelli S. A. y Frechiani de Oliveira G. - "As principais teorias ...

lles, quatrième 15:177-253.

LEROI-GOURHAN, A. 1968. The Art of Prehistory man in Western Europe. Thames and Hudson, London.

LEROI-GOURHAN, A. 2001. Os caçadores da pré-história. Edições 70, Lisboa.

LEWIN, R. 1999. Evolução Humana. Atheneu, São Paulo.

LEWIS-WILLIAMS, D. 2005. La mente en la caverna. Akal, Madrid.

LOWIE, R. 1972. La Sociedad Primitiva. Trad. Ariel Bignami. Amorroto, Buenos Aires.

MAGALHÃES, S.M. 2001. Arte rupestre do centro-norte do Piauí: indices de narrativas cônicas. Tese Doutorado em História, Universidade Federal Fluminense, Instituto de Ciências Humanas e Filosofia, Rio de Janeiro,

MARANCA, S. y MARTIN, G. 2014. Populações pré-históricas ceramistas na região da Serra da Capivara. En Os Biomas e as Sociedades Humanas na Pré-história da região do Parque Nacional Serra da Capivara, editado por A. Pessis, N.Guidon y G. Martin, pp. 480511. A\&A Comunicação, São Paulo.

MARINGER, J. y H.G. BANDI. 1952. Arte prehistorico: las cavernas, el levante, las regiones articas. Holbein, Basileia.

MARTINEZ, V.M.F. 2014. Prehistoria: El largo caminho de la humanidad. Alianza Editorial, Madrid.

MORTILlET, G. y A. 1910. La Préhistoire. Origine et Antiquité de l'Homme. Librairie Schleicher Frères, París

NADER, R.A. 2014. Arqueoastronomia. En Olhando o Céu da Pré-história: Registros Arqueoastronômicos no Brasil, editado por C. Jalles y M. Imazio, pp 1.15-18. Museu de Astronomia e Ciências Afins, Rio de Janeiro.

OLIVEIRA, J.F. 2013. A Arqueoacústica: um estudo de caso no Sítio Martiliano, Parque Nacional Serra da Capivara- PI. En II Semana Internacional de Arqueologia Andre Penin vol. 1, p. 42. Universidade de
São Paulo, São Paulo.

PELLINI, J.R. 2010. Mudando o coração, a mente e as calças. Arqueologia Sensorial. Revista do Museu de Arqueologia e Etnologia da Universidade de São Paulo 20:3-16.

PELLINI, J.R. 2016. Arqueologia e os sentidos: entrando na toca do coelho. Editora Prismas, Curitiba.

PIAGET, J. 1978. Os pensadores. J. Piaget. Abril Cultural, São Paulo.

PUCCI, M. 2006. A voz e a pedra: rupestres sonoros do Mawaca. En Terra Brasilis: Pré-História e arqueologia da psique, editado por M. Calila e M. Fleury de Oliveira, pp. 259-274. Editora Paulus, São Paulo.

REICHEL-DOLMATOFF, G. 1976. O Contexto Cultural de um Alucinógeno Aborígine: Banisteriopsis Caapi. En Os alucinógenos e o mundo simbólico, editado por C. Vera Penteado, pp.59-104. EDUSP, São Paulo.

REFREW, C. y P. BAHN. 1993. Arqueologia: Teorias, métodos y práctica. Akal, Madrid.

RIFKIN, R. 2009. Engraved art and acoustic resonance: exploring ritual and sound in north-western South Africa. Revista Antiquity 83:585-601.

SANCHIDRIÁN, J.L. 2005. Manual de Arte Pré-histórico. Editorial Ariel S.A, Barcelona.

SCHADEN, E. 1959. A mitologia heroica de tribos indigenas do Brasil. Ministério da educação e cultura, Rio de Janeiro.

SCHADEN, E. 1969. Aculturação indigena. Enio Matheus Guazzelli, São Paulo.

SCHMITD, W. 1942. Ethnologia Sul-Americana. Companhia Editora Nacional, Rio de Janeiro.

SCHMITZ, P.I.; A.S. BARBOSA y M.B. RIBEIRO. 1997. Arqueologia nos cerrados do Brasil Central: Serranópolis: Pinturas e Gravuras dos Abrigos. Instituto Anchietano de Pesquisas/ Unisinos 65. SHANKS, M. y C. TILLEY. 1992 Re-Con- 
structing Archaeology: Theory and Practice. Press Syndicate of the University of Cambridge, Cambridge.

STERNBERG, R.J. 2000. Psicologia Cognitiva. Artes Médicas Sul, Porto Alegre.

TYLOR, E.B. 1903. Primitive culture: researches into the development of mythology, philosophy, religion, language, art and custom. John Murray, Londres.

WAGLEY, C. 1976. Xamanismo tapiraré. En Leituras de etnologia brasileira, editado por E. Schaden, pp. 236-267. Companhia Editora Nacional, São Paulo.

WHITLEY, D. 2005. Introduction to Rock Art Research. Left Coast Press, Walnut Creek. 